\author{
CHILD CARE SERVICE \\ 93RD APSA Annual Meeting \\ Washington, DC \\ August 28-31, 1997
}

The American Political Science Association will sponsor a Child Care Service at the 93rd Annual Meeting in Washington, DC. Child care will be available daily in the Sheraton Washington from Thursday, August 28 through Sunday, August 31. The hours of operation are from 8:30am to $10: 30 \mathrm{pm}$ except on Sunday, August 31 when the hours of operation will be from 8:30am to $12: 30 \mathrm{pm}$.

KiddieCorp child care is available for unlimited use to children of registrants at the 1997 Annual Meeting. Parents will be asked to complete a tentative schedule following confirmation of their child care service registration. Nutritious snacks and beverages will be provided. Breakfast, lunch and dinner must be provided by the parents. Diapers, special milk or formula, as well as any written special feeding instructions should be supplied by the parents.

To participate in the child care service, follow these instructions:

1. Complete the child care registration form below and submit it to APSA by July 15 , 1997.

2. A $\$ 50.00^{*}$ fee is required for each registered child if you are a professional member, associate member or family member. A $\$ 35.00^{*}$ fee is required for each registered child if you are a graduate student member. Payment must be made with the submission of the child care registration form.

*Pending APSA Council approval in April 1997.

3. All registration forms and payments must be received at APSA by July 15, 1997 . There will be limited on-site registration. On-site registration will require a $\$ 65.00$ fee per child if you are a professional member, associate member or family member. The on-site registration fee for graduate student members is $\$ 50.00$ per child. APSA does not guarantee space for children registered on-site.

KiddieCorp staffing will be provided according to the following state-regulated staff to child ratios:

$1: 2$ ratio for children 6 months * to 1 year old

$1: 3$ ratio for children 1 to 3 years old

$1: 5$ ratio for children over 3 years old

*Please Note: Minimum age for the child care service is 6 months.

\title{
CHILD CARE REGISTRATION FORM
}

Name of Parent:

Home Address:

Daytime Phone \#:

List child/children:

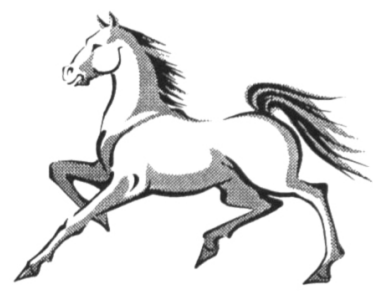

Mail to:

Name:

Age:

Child Care Coordinator

$\square$ Name:

Age:

APSA

1527 New Hampshire Ave, NW Washington, DC 20036

Age: 